University of Nebraska - Lincoln

DigitalCommons@University of Nebraska - Lincoln

Faculty Publications: Department of Entomology

Entomology, Department of

$4-29-2020$

\title{
Comparative effects of technical-grade and formulated chlorantraniliprole to the survivorship and locomotor activity of the honey bee, Apis mellifera (L.)
}

Jennifer R. Williams

University of Nebraska-Lincoln, jwilliams91@unl.edu

Daniel R. Swale

Louisiana State University, dswale@agcenter.Isu.edu

Troy D. Anderson

University of Nebraska-Lincoln, tanderson44@unl.edu

Follow this and additional works at: https://digitalcommons.unl.edu/entomologyfacpub

Part of the Entomology Commons

Williams, Jennifer R.; Swale, Daniel R.; and Anderson, Troy D., "Comparative effects of technical-grade and formulated chlorantraniliprole to the survivorship and locomotor activity of the honey bee, Apis mellifera (L.)" (2020). Faculty Publications: Department of Entomology. 852.

https://digitalcommons.unl.edu/entomologyfacpub/852

This Article is brought to you for free and open access by the Entomology, Department of at DigitalCommons@University of Nebraska - Lincoln. It has been accepted for inclusion in Faculty Publications: Department of Entomology by an authorized administrator of DigitalCommons@University of Nebraska - Lincoln. 


\title{
Comparative effects of technical-grade and formulated chlorantraniliprole to the survivorship and locomotor activity of the honey bee, Apis mellifera (L.)
}

\author{
Jennifer R. Williams, ${ }^{1}$ Daniel R. Swale, ${ }^{2}$ \\ and Troy D. Anderson ${ }^{1}$ \\ 1 Department of Entomology, University of Nebraska-Lincoln, Lincoln, NE, USA \\ 2 Department of Entomology, Louisiana State University AgCenter, \\ Baton Rouge, Louisiana, USA \\ Correspondence: T.D. Anderson, Department of Entomology, University of Nebraska-Lincoln, \\ 103 Entomology Hall, Lincoln, NE, 68583, USA; email tanderson44@unl.edu
}

\begin{abstract}
Background: The loss of honey bee colonies is a nationally recognized problem that demands attention from both the scientific community and the beekeeping industry. One outstanding threat is the unintended exposure of these pollinators to agricultural pesticides. Anthranilic diamides, such as chlorantraniliprole, are registered for use in stone and pome fruits, vegetables, turf, and grains. There are few publicly available studies that provide an analysis of chlorantraniliprole effects on the survivorship and locomotion activity of beneficial, pollinating insects such as honey bees. The data gathered in this study provide the acute toxicity, 30-day survivorship, and locomotor activity of honey bees exposed to technical-grade chlorantraniliprole and three formulated products with chlorantraniliprole as the active ingredient.
\end{abstract}

Published in Pest Management Science 76 (2020), pp 2582-2588

doi:10.1002/ps.5832

Copyright $\odot 2020$ Society of Chemical Industry; published by Wiley. Used by permission. Submitted 16 December 2019; revised: 27 February 2020; accepted 1 April 2020; published 29 April 2020. 
Results: Neither the technical-grade nor the formulated products of chlorantraniliprole were acutely toxic to honey bees following 4 or $72 \mathrm{~h}$ treatments at the tested concentrations. A 4 h treatment of technical-grade and formulated chlorantraniliprole did not significantly affect the 30-day survivorship, although significantly higher mortality was observed after 30 days for bees receiving a $72 \mathrm{~h}$ treatment of technical-grade chlorantraniliprole and two formulated products. The locomotion activity, or total walking distance, of bees receiving a $4 \mathrm{~h}$ treatment of one chlorantraniliprole formulation was significantly reduced, with these individuals recovering their normal locomotion activity at $48 \mathrm{~h}$ post exposure. Conversely, there was observed lethargic behavior and significantly reduced walking distances for bees provided with a $72 \mathrm{~h}$ treatment of technicalgrade chlorantraniliprole and each formulated product.

Conclusion: This study provides evidence for the effect of long-term exposure of chlorantraniliprole on the survivorship and locomotor activity of honey bees. Bees receiving a more field-relevant short-term exposure survived and moved similarly to untreated bees, reiterating the relative safety of chlorantraniliprole exposure to adult honey bees at recommended label concentrations.

Keywords: honey bee; diamide insecticide; chlorantraniliprole; survivorship; locomotor activity

\section{Introduction}

Honey bees are the most widely managed pollinator in the world due to their amenability to manipulation within a hive and generalist foraging capabilities. The value of crop plant species in the USA is enhanced by approximately US $\$ 15$ billion a year through animal pollination and approximately $75 \%$ of that value comes directly from pollination services provided by honey bees. ${ }^{1,2}$ While global numbers of managed colonies have risen since the 1950s, these increases are observed primarily in developing areas of the globe and at a rate that is unsustainable for the growing demand of pollination services. ${ }^{3,4}$ The regional loss of managed bee colonies and native pollinators due to multiple interacting stressors is a concern in the USA and Europe. 5,6 Managed bee colonies are routinely exposed to both apicultural and agricultural pesticides. While vital to the productivity of agriculture, pesticide exposures are reported to be an important factor in the loss of managed bee colonies by beekeepers. ${ }^{7}$ Within bee hive matrices, beekeeper-applied acaricides used to manage Varroa mite infestations and multiple agricultural pesticides are transported from field sources of food and water to the hive by foraging bees. ${ }^{8-10}$ The 
continuous exposure of honey bees to apicultural and agricultural pesticides within and outside of the hive has prompted investigation into the deleterious effects these chemical exposures may have on individual bees and the colony. ${ }^{11-24}$

The ryanodine receptor modulating diamides are the most recently registered mode of insecticidal action [Insecticide Resistance Action Committee (IRAC) class 28] and represent $8 \%$ of the agrochemical market, with increased usage each year. ${ }^{25}$ The ryanodine receptor is a ligand-gated calcium channel found in the endo- or sarcoplasmic reticulum of neuromuscular cells. Anthranilic diamides, such as chlorantraniliprole, are effective against insect pests via ryanodine receptor activation, which leads to an uncontrolled release of cellular calcium. This rapid depletion of internal calcium stores results in feeding cessation, uncontrolled muscle contraction, lethargy, paralysis, and eventual death after approximately 48-72 h. ${ }^{26-28} \mathrm{Ch}$ lorantraniliprole binding to the ryanodine receptor is hypothesized to be selective toward a wide range of crop-chewing insect pests, particularly lepidopteran species, compared to other insects, such as dipteran and hymenopteran species. ${ }^{29}$ This selective binding of chlorantraniliprole on lepidopteran ryanodine receptors over other insect orders is reported to be due in part to a $14790 \mathrm{M}$ difference in the Hymenoptera and in the transmembrane-spanning region of the receptor reported to contain the diamide binding site. ${ }^{30,31}$ Due to the decreased binding of chlorantraniliprole to the ryanodine receptor of Hymenoptera, this diamide insecticide exhibits low toxicity to bees and was granted reduced risk status by the United States Environmental Protection Agency (US EPA) in 2007 at the time of registration. Currently, there are multiple formulated products of chlorantraniliprole on the market registered for use in pome and stone fruits, almonds, grains, cucurbits, fruiting and leafy vegetables, turf, and ornamentals. Chlorantraniliprole may be used as an aerial or foliar spray, in furrow, or as a seed treatment. The muscular target of chlorantraniliprole, in addition to the increasing likelihood of exposure to the insecticide, necessitates an examination of sublethal endpoints in beneficial, pollinating insects. However, there are relatively few studies that have investigated the sublethal effects of chlorantraniliprole exposure to honey bees.

A 2009 study reported the acute toxicity and semi-field exposure effects to honey bees following oral and contact exposure to the 
technical-grade and two formulated products of chlorantraniliprole, 20SC and 35WG. ${ }^{32}$ Bees exposed orally or through contact application to the active ingredient or 20SC were observed to be lethargic following exposure but recovered after 48 to 72 h. ${ }^{32}$ Under semi-field conditions Dinter et al. ${ }^{32}$ also reported no significant differences in the number of foraging bees entering and exiting the hive, flying in the field, or dead individuals following exposure to a chlorantraniliprole formulation compared to untreated bees. Another study on Bombus impatiens found no alteration in returning forager numbers or mortality, and comparable weight gain between chlorantraniliprole treated and untreated colonies in weedy turf. ${ }^{33}$ In addition, Larson et al. observed no adverse effects of chlorantraniliprole-treated turf to four beneficial insects. ${ }^{34} \mathrm{Zhu}$ et al. found the chlorantraniliprole formulation $5 \mathrm{SC}$ to be the least toxic insecticide of 42 row crop pesticides sprayed on adult bees. ${ }^{35}$ While many studies do not report negative effects of chlorantraniliprole to pollinating insects, Smagghe et al. found that a chronic exposure to the chlorantraniliprole formulation 20SC in pollen suppressed the production of drone bumble bees and increased lethargy in the worker population for the duration of the exposure. ${ }^{36}$ Additionally, Kadala et al. found that bees topically exposed to technical-grade chlorantraniliprole experienced an initial decrease in locomotion, apparent recovery the following day, and another marked decrease in motion 7 days post exposure. ${ }^{37}$

The aim of this study was to examine lethal and sublethal endpoints of bees exposed to technical-grade and three formulated products of chlorantraniliprole. Although chlorantraniliprole is not reported to be acutely toxic to bees, the increasing agricultural, horticultural, and ornamental uses of products containing the insecticide increase the likelihood of exposure to beneficial, pollinating insects. The effects of chlorantraniliprole exposure on locomotor activity may have downstream behavioral deficits that compromise the ability of honey bees to complete essential hive tasks, including flying, foraging, or pollinating activities. Here, we report the acute toxicity, survivorship, and locomotor activities of honey bees exposed to technical-grade and formulated chlorantraniliprole. Honey bees were exposed to chlorantraniliprole in the laboratory for either 4 or $72 \mathrm{~h}$ to compare exposure lengths and ascertain the bee's ability to recover from an acute exposure to chlorantraniliprole. 


\section{Materials and methods}

\subsection{Subjects}

The European honey bee (Apis mellifera L.) was used for all laboratory experiments. Unless otherwise stated, adult bees were collected from the brood nest of hives maintained by the Department of Entomology at the University of Nebraska (Lincoln, NE, USA) using standard beekeeping practices with no miticide applications, antibiotic treatments, or supplemental pollen feeding in the months prior to sampling. The bees were transported to the laboratory, placed into $10.16 \times 7.62 \times$ $7.62 \mathrm{~cm}$ acrylic glass cages with holes drilled in to provide ventilation, and maintained in an environmental incubator at $30^{\circ} \mathrm{C}$ with 60 $80 \%$ relative humidity in the dark. The bees were fed ad libitum with a $50 \%$ sucrose solution $(\mathrm{w} / \mathrm{v})$ overnight in microcentrifuge tubes with holes drilled in them. If higher than $10 \%$ overnight mortality was observed for untreated bees, the collection and caging procedure was repeated with a new group of bees. Technical-grade chlorantraniliprole was dissolved in dimethyl sulfoxide (DMSO) and then diluted in a $50 \%$ sucrose solution to a final concentration of $150 \mathrm{mg} \mathrm{L}^{-1}(\mathrm{w} / \mathrm{v} ; 2 \%$ DMSO final concentration) whereas aliquots of the formulated products were taken directly from the manufacturer's container and diluted in a $50 \%$ sucrose solution $(\mathrm{v} / \mathrm{v})$. The exposure concentration for each formulated product was based on conversion of the highest recommended concentration of active concentrate per unit area (in gallons) on the manufacturer's label to $\mathrm{mg} \mathrm{L}^{-1}$. Unless otherwise noted, experimental treatments contained an untreated control ( $50 \%$ sucrose), solvent control ( $50 \%$ sucrose containing $2 \%$ DMSO v/v), $805 \mathrm{mg} \mathrm{L}^{-1}$ of chlorantraniliprole 5SC, $1172 \mathrm{mg} \mathrm{L}^{-1}$ of chlorantraniliprole 20SC, and $392 \mathrm{mg} \mathrm{L}^{-1}$ of chlorantraniliprole 35WG.

\subsection{Chemicals}

Technical-grade chlorantraniliprole (5-bromo- $N$-[4-chloro-2-methyl-6(methylcarbamoyl)phenyl]-2-(3-chloropyridin-2-yl) pyrazole-3-carboxamide, 98.30\%) and malathion (diethyl 2-[(dimethoxyphosphorothioyl) sulfanyl]butanedioate, 99.24\%) were purchased from Chem Service Inc. (West Chester, PA, USA), and chlorantraniliprole 5SC (Prevathon 
5SC, $5 \%$ active ingredient (a.i.) or $52 \mathrm{~g} \mathrm{~L}^{-1}$ ), chlorantraniliprole $20 \mathrm{SC}$ (Coragen 20SC, 18.4\% a.i. or $200 \mathrm{~g} \mathrm{~L}^{-1}$ ), and chlorantraniliprole 35WG (Altacor, 35\% a.i. or $350 \mathrm{~g} \mathrm{~kg}^{-1}$ ) were provided in kind from DuPont (Wilmington, DE, USA). DMSO was purchased from Sigma-Aldrich (St. Louis, MO, USA).

\subsection{Acute toxicity}

The lethal concentrations of technical-grade and formulated chlorantraniliprole to bees were estimated by oral administration in a $50 \%$ sucrose solution (w/v) as described in Section 2.1. The chlorantraniliprole treatments consisted of six concentrations. Ten bees per replicate, with three replicates, were used for each concentration and each experiment was duplicated. Bees were provided with a $4 \mathrm{~h}$ treatment of technical-grade or formulated chlorantraniliprole, then the chlorantraniliprole treatments were replaced with an untreated sucrose solution after the $4 \mathrm{~h}$ period. Another group of bees were provided a $72 \mathrm{~h}$ treatment of technical-grade or formulated chlorantraniliprole and no replacement with untreated sucrose solution for the $72 \mathrm{~h}$ period. Chlorantraniliprole is a slow-acting insecticide compared to other modes of action, such as the organophosphate malathion, and thus at each time point the bees were observed and signs of toxicity or intoxication were noted.

\subsection{Survival curves}

The survivorship of bees was monitored for 30 days following 4 and $72 \mathrm{~h}$ oral administration of technical-grade and formulated chlorantraniliprole in a 50\% sucrose solution (w/v) as described in Section 2.1. To collect emerging bees, frames were taken from hives and transported to the laboratory where they were maintained in an environmental chamber at $33^{\circ} \mathrm{C}$ with $60-70 \%$ relative humidity. The newly emerged bees were collected and placed into $10.16 \times 7.62 \times 7.62 \mathrm{~cm}$ acrylic glass cages with honey, pollen (Bee-Pro Patties, Brushy Mountain Bee Farm, NC, USA), and water provided ad libitum for 2 days. The honey and water were then replaced with either technical-grade or formulated chlorantraniliprole in sucrose solution. The $4 \mathrm{~h}$ treatments consisted of six cages with 30 bees per cage and the $72 \mathrm{~h}$ treatments 
consisted of eight cages with 30 bees per cage. Following the 4 and $72 \mathrm{~h}$ periods, the technical-grade and formulated chlorantraniliprole treatments were replaced with untreated sucrose solution. The pollen was removed after 8 days and mortality was recorded each day for 30 days. Each experiment was replicated three times. The organophosphate insecticide malathion was used as a toxic reference $\left(40 \mathrm{mg} \mathrm{L}^{-1}\right.$ in $2 \%$ acetone $(\mathrm{v} / \mathrm{v}))$ to test the validity of the experiment up to $72 \mathrm{~h}$.

\subsection{Locomotor activity}

The locomotor activity of bees was evaluated following 4 and $72 \mathrm{~h}$ oral administration of technical-grade and formulated chlorantraniliprole in a $50 \%$ sucrose solution $(\mathrm{w} / \mathrm{v})$. The treatments consisted of six cages with 30 bees per cage and each experiment was replicated three times. The locomotor activity was measured as the total distance traveled by the bees using a modified videotracking protocol described by Larson and Anderson. ${ }^{38}$ Following the 4 and $72 \mathrm{~h}$ treatments, 60 bees were randomly selected and transferred to $10-\mathrm{cm}$ diameter polystyrene Petri dishes (i.e. one bee per dish). A Basler acA-1300-60gm camera and EthoVision XT video recording software was used to record the total distance traveled by the bees in the Petri dishes (Noldus Information Technology Inc. Leesburg, VA, USA). A light box was used to illuminate the assay arena with LED light (Armacost Lighting, Baltimore, $M D, U S A)$ set to the red spectrum in order to avoid light bias of the bees. The light box and camera system were covered with a black plastic sheet to eliminate ambient light. The dishes were positioned on top of a light box in a $4 \times 3$ grid pattern. The walking distance of the bees was recorded for 15 min intervals. The bees were differentiated from their background in the software program using dynamic subtraction of the pixels delineating the subject from the background. The software scanned each arena 25 times per second to determine the positions of the bees as time-series coordinates $(x, y)$ within each arena. These coordinates were translated into actual distances by calibrating the program to the physical dimensions of the Petri dish arena. A total of 20 bees per replicate ( $n=60$ per treatment) were recorded for each time point to determine changes in locomotion activity and total walking distance $(\mathrm{cm})$ was calculated by the software and analyzed in GraphPad Prism 8 (GraphPad Software, San Diego, CA, USA). 


\subsection{Statistical analysis}

All analyses and calculations were conducted using GraphPad Prism 8 (GraphPad Software). Survivorship was reported using Kaplan-Meier survival curves, displaying mean values \pm standard error, with significant differences between the survival curves determined by the logrank (Mantel-Cox) test. For locomotion assays, walking distances in bees exposed to technical-grade and formulated chlorantraniliprole were compared to their relative control (solvent and untreated control, respectively) for each time point. The data were analyzed with a two-way analysis of variance with post hoc Sidak's multiple comparison test $(P<0.05)$ to determine differences between solvent control and technical-grade chlorantraniliprole treatments, or a two-way analysis of variance with post hoc Dunnett's multiple comparison test $(P$ $<0.05)$ to determine differences between the untreated controls and formulated chlorantraniliprole treatments.

\section{Results}

\subsection{Acute toxicity}

There was $\leq 20 \%$ mortality observed for bees provided with continuous treatment of chlorantraniliprole 5SC (2.17 \pm 1.17 bees per cage, $13 / 60$ bees total), whereas no mortality was observed for bees provided with the other treatments. However, after $24 \mathrm{~h}$, uncoordinated movement, lethargy, and trembling were observed in bees provided with the highest treatments of technical-grade and formulated chlorantraniliprole for $4 \mathrm{~h}$. These intoxication symptoms subsided by $48 \mathrm{~h}$. The bees treated with technical-grade and formulated chlorantraniliprole for $72 \mathrm{~h}$ displayed the same symptomologies after $24 \mathrm{~h}$ of treatment, with these symptoms continuing for the duration of the experiment. The $\mathrm{LC}^{50}$ was not estimated for technical-grade chlorantraniliprole or the tested formulations at the label concentration due to the low mortality observed. 


\subsection{Survival curves}

The survivorship of bees treated with technical-grade and formulated chlorantraniliprole for $4 \mathrm{~h}$ (Fig. 1(A),(B)) or $72 \mathrm{~h}$ (Fig. 1(C),(D)) was monitored for 30 days. There were no significant differences observed for bees treated with technical-grade or formulated chlorantraniliprole for $4 \mathrm{~h}$ compared to the solvent-treated and untreated bees (Fig. 1(A),(B), $P=0.18, P=0.14$ ). However, the 72 -h treatment of technical-grade chlorantraniliprole significantly decreased the survivorship of bees compared to the solvent treatment (Fig. 1(C), $P=$ 0.0008 ). Similarly, there was a significant reduction in survivorship for

(a)

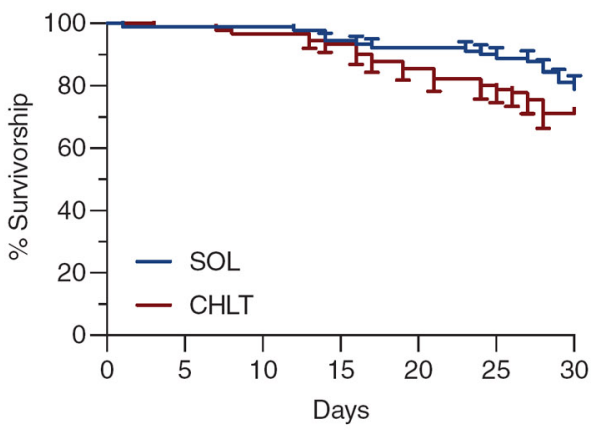

(b)

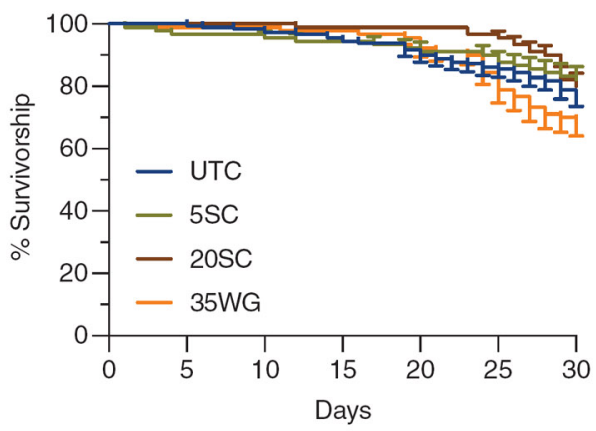

(c) 72-h Treatment

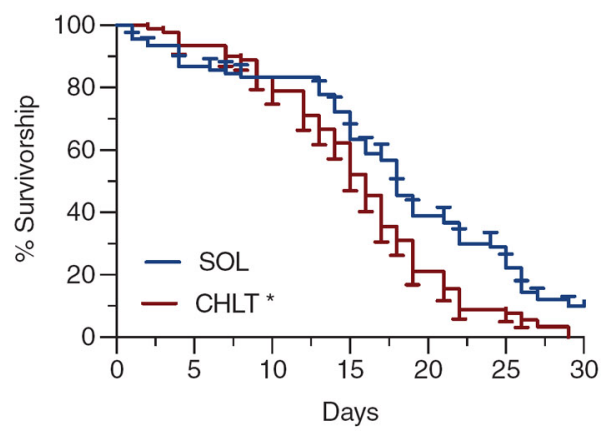

(d)

72-h Treatment

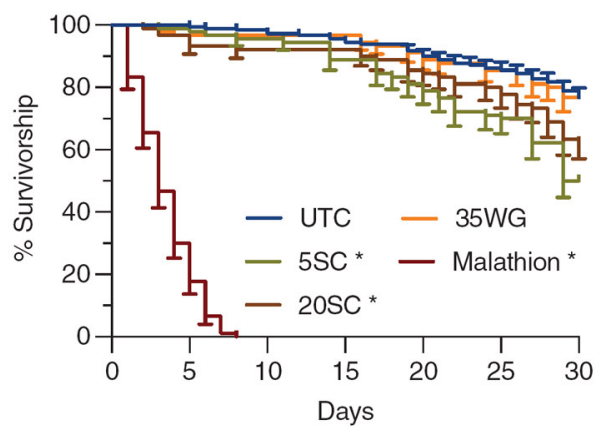

Figure 1. Percentage survivorship of honey bees treated with technical-grade $(a, c)$ and formulated chlorantraniliprole $(b, d)$ for 4 and $72 \mathrm{~h}$. The data are presented as Kaplan-Meier survivorship curves with time points representing the mean \pm standard deviation of solvent (SOL) or untreated control (UTC) $(n=180)$ and treated with technical-grade and formulated chlorantraniliprole (CHLT; 5SC, 20SC, 35 WG) $(n=90)$. Malathion was used as a toxic reference. Significant differences between the chlorantraniliprole survival curves and their relative controls determined by the log-rank (Mantel-Cox) test and designated with an asterisk. 
bees provided with the $72 \mathrm{~h}$ treatment of two formulated chlorantraniliprole products when compared to the untreated bees (Fig. 1(D), 5SC: $P<0.0001$; 20SC: $P=0.0112$ ) The survivorship of bees treated with one formulated product of chlorantraniliprole for $72 \mathrm{~h}$ was not significantly altered over the 30 -day period (35WG: $P=0.98$ ). All bees provided the toxic reference malathion $\left(40 \mathrm{mg} \mathrm{L}^{-1}\right)$ were deceased by day 8 of the study.

\subsection{Locomotor activity}

The walking distance of bees treated with technical-grade and formulated chlorantraniliprole for 4 or $72 \mathrm{~h}$ was monitored at 24, 48, and $72 \mathrm{~h}$. The walking distances of bees provided with $4 \mathrm{~h}$ treatments of technical-grade and formulated chlorantraniliprole are shown in Fig. $2(A),(B)$. At 48 and 72 h, the walking distance of bees treated with technical-grade chlorantraniliprole was significantly reduced compared to solvent control bees (48 $\mathrm{h}$ : $-58.63 \%$ (percentage change relative to control), $P<0.0001 ; 72$ h: $-82.33 \%$; $P<0.0001$ ) (Fig. 2(A)). The walking distances of bees treated with formulated chlorantraniliprole for $4 \mathrm{~h}$ were not significantly reduced compared to those of the untreated bees, with the exception of the bees treated with 35WG, which traveled less distance than the untreated bees after $24 \mathrm{~h}(-17.83 \%$, $P=0.0481$ ) (Fig. 2(B)). The walking distances of bees treated with technical-grade and formulated chlorantraniliprole for $72 \mathrm{~h}$ are shown in Fig. 2(C),(D). At $24 \mathrm{~h}$, the walking distance of bees treated with technical-grade chlorantraniliprole was significantly reduced compared to that of untreated bees ( $-38.84 \%, P=0.0002$ ) (Fig. 2(C)). However, the walking distances of bees treated with 5SC, 20SC, and 35WG for $72 \mathrm{~h}$ were significantly decreased compared to those of the untreated bees (24 h treatments: 5SC $-52.38 \%, P<0.0001$; 20SC $-57.03 \%$, $P<0.0001$; 35WG $-50.19 \%, P<0.0001 ; 48$ h treatments: 5 SC $-51.56 \%$, $P<0.0001$; 20SC - 36.80\%, $P<0.0001$; 35WG - 33.45\%, $P<0.0001$; 72 h treatments: 5SC $-19.75 \%, P=0.0119 ; 20 S C-35.77 \%, P<0.0001$; 35WG $-30.77 \%, P<0.0001$ ) (Fig. 2(D)). 
(a)

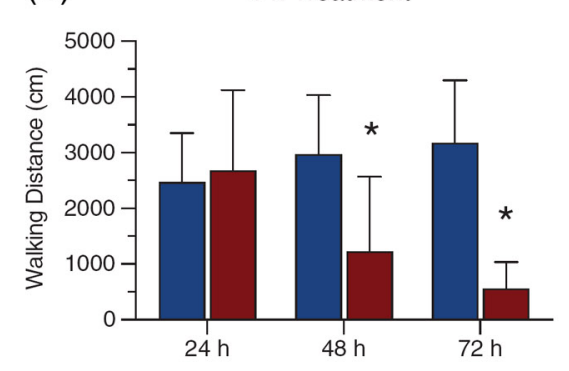

(b)

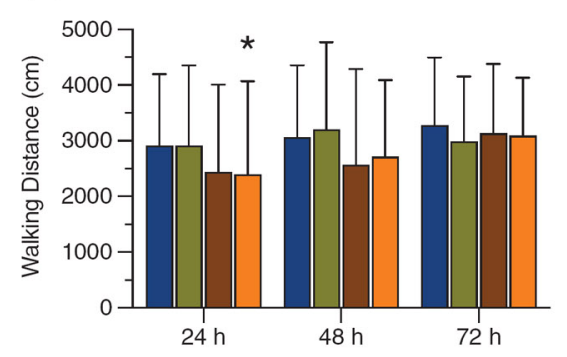

(c) 72-h Treatment

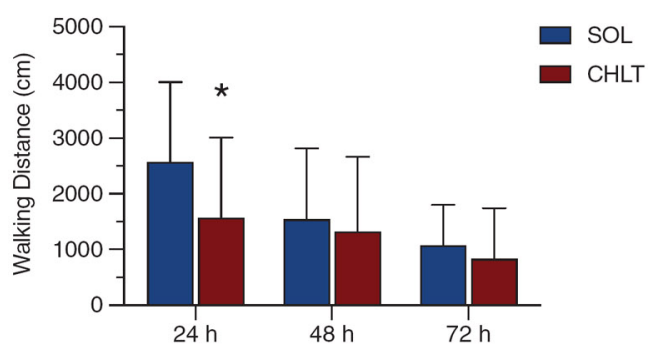

(d)

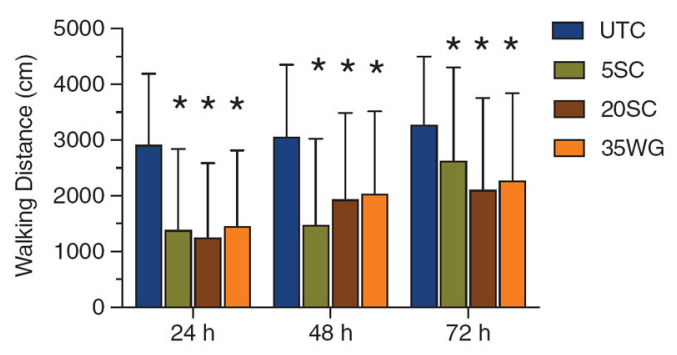

Figure 2. Walking distance of honey bees treated with technical-grade $(a, c)$ and formulated chlorantraniliprole $(b, d)$ for 4 and $72 \mathrm{~h}$. The data are presented as the mean \pm standard deviation of solvent (SOL) or untreated control (UTC) and treated with technical-grade and formulated chlorantraniliprole (CHLT; 5SC, 20SC, 35 WG) (n $=60$ ). Asterisks above the bars indicates the treatment mean is significantly different from the SOL or UTC using two-way ANOVA with Sidak's (technical grade CHLT vs. SOL) or Dunnett's (formulated CHLT vs UTC) multiple comparison tests $(P<0.05)$.

\section{Discussion}

Agricultural, horticultural, and ornamental usage of chlorantraniliprole increases each year and the formulated products are labeled for usage on several flowering plants and crops that are known to be visited by bees. ${ }^{25}$ The frequent exposure to agrochemicals warrants investigation into the sublethal effects that active ingredients and formulated products may have on honey bees. This study aimed to bridge current knowledge gaps regarding the effects of chlorantraniliprole exposure on honey bees. Due to the reduced binding activity of chlorantraniliprole to the ryanodine receptor in bees, ${ }^{29}$ we hypothesized the insecticide to have low acute toxicity and no effects on locomotor activity with treated individuals. 
We provided bees with a continuous oral treatment of technicalgrade and formulated products of chlorantraniliprole for 4 and $72 \mathrm{~h}$ and monitored survivorship ( $\leq 30$ days post treatment) and locomotor activity ( $<3$ days post treatment). After the $72 \mathrm{~h}$ period, we observed $20 \%$ mortality $(2.17 \pm 1.17$ dead bees per cage, $13 / 60$ bees in total) for bees treated with chlorantraniliprole 5SC whereas no other treatment or exposure period of chlorantraniliprole was found to be lethal to the bees. However, those honey bees treated with each chlorantraniliprole treatment for $72 \mathrm{~h}$ showed intoxication and lethargy after 1 day, with a continuation of these symptomologies for the duration of the experiment. These data parallel previous evidence for the low toxicity of chlorantraniliprole to bees as well as previous studies that observed no increased mortality of bees exposed to technical-grade or formulated chlorantraniliprole, ${ }^{32,33,35}$ although Dinter et al. did observe lethargic bees following exposure to technical-grade and formulated chlorantraniliprole. The daily mortality of bees exposed to technicalgrade or formulated chlorantraniliprole was recorded for 30 days after the 4 or $72 \mathrm{~h}$ exposure periods. Those bees treated with technical-grade or formulated chlorantraniliprole for $4 \mathrm{~h}$ did not experience significantly different survival curves but the survival curves of bees exposed to technical-grade chlorantraniliprole and two of three formulated products experienced significantly decreased survival compared to untreated controls after $72 \mathrm{~h}$ of exposure. Lastly, we provided bees with a continuous, oral treatment of technical-grade and formulated products of chlorantraniliprole for 4 and $72 \mathrm{~h}$ and monitored locomotor activity (i.e. walking distance). After the $4 \mathrm{~h}$ treatment, we observed a reduction in walking distance for bees treated with the formulated product 35WG after $24 \mathrm{~h}$. However, there were no significant differences between the treated and untreated honey bees after the 48- and 72-h periods. These data suggest that the bees are able to recover locomotor activity following short-term exposure to chlorantraniliprole. A similar study treated honey bees with a sublethal dose of chlorantraniliprole and observed a decrease in distance traveled and mobility after 6 and $24 \mathrm{~h}$ of treatment. ${ }^{37}$ The bees in that study recovered their mobility after $48 \mathrm{~h}$ similar to that of the untreated bees, but lost mobility 7 days later. However, we observed a reduction in distance travelled for bees treated with chlorantraniliprole for $72 \mathrm{~h}$ compared to the untreated bees, with no recovery of their mobility. The lethargic behavior and decreased walking distance of the 
bees is presumed to be due to the high concentrations and exposure periods of chlorantraniliprole used for this study. It is hypothesized that these concentrations of chlorantraniliprole may prolong the activation of the ryanodine receptor and, in turn, affect the walking distance of the bees, although the effects might be reversed for individuals exposed to the insecticide for short periods of time.

It is important to note that the bees were treated with nominal concentrations of technical-grade or formulated product of chlorantraniliprole and the consumption of sucrose solution treated with each product was not recorded, which is a limitation of this study. Additionally, it is an inherent challenge to correlate pesticide-induced effects for laboratory-treated individuals to those outcomes that might adversely affect the colony. ${ }^{39,40}$ This is due to the fact that insecticidal action in bees is a function of the physical properties of the chemistry, its application and environmental fate, and the foraging behaviors of bees that expose them to the insecticide..$^{39,41}$ It is unlikely that bees would be exposed to the highest label recommended concentration of an insecticide in the field due to a number of factors, including formulation type, method of application, drift, and environmental degradation..$^{42}$ Additionally, honey bee-specific behaviors such as trophallaxis, wherein food resources are shared among nestmates, ensures that while additional individuals receive contaminated pollen or nectar, the dose reaching each individual is continuously diluted in the process. ${ }^{39}$ The prolonged and decreased locomotor activity observed with the chlorantraniliprole-treated bees for this study may be the result of the high exposure concentrations. Additionally, the $72 \mathrm{~h}$ of continuous exposure to one food source treated with an insecticide is not a common scenario for natural bee colonies and thus we chose short-term ( $4 \mathrm{~h}$ ) and long-term (72 h) exposure periods for this study. The concentrations and long exposure period used in this study represent a worst-case scenario unlikely to be experienced by honey bees in the field.

The low solvent solubility of chlorantraniliprole presented another challenge to this study and affected the survivorship and locomotor activity of bees treated with the technical-grade chlorantraniliprole and solvent alone after a continuous $72 \mathrm{~h}$ of exposure. The bees were treated with technical-grade chlorantraniliprole that was dissolved in DMSO, which was then diluted in $50 \%$ sucrose solution, resulting in a final solvent concentration of $2 \%$. While bees exposed to 
technical-grade chlorantraniliprole or solvent control for $4 \mathrm{~h}$ survived over 30 days at a rate similar to untreated controls, the same could not be said for bees exposed for $72 \mathrm{~h}$. This long exposure resulted in differential survival curves for both solvent control and technical-gradetreated bees compared to untreated bees. Additionally, solvent control and technical-grade-treated bees moved significantly slower than untreated control bees in the locomotion trials. For these reasons, the data herein are presented separately as technical-grade chlorantraniliprole with related solvent control and formulated products with untreated control for each exposure scenario. In this study a $4 \mathrm{~h}$ exposure to solvent control and active ingredient resulted in significantly decreased movement in active ingredient-treated bees at 48 and 72 h compared to solvent control, whereas bees treated with active or solvent continuously for $72 \mathrm{~h}$ experienced parallel decreased movement at 24, 48, and 72 h, with significant differences between technical-grade and solvent visible only at $24 \mathrm{~h}$. The effects of DMSO on survivability and locomotion of bees, especially those bees exposed continuously for $72 \mathrm{~h}$ led to unfortunate difficulty in differentiating between true effects of the active ingredient chlorantraniliprole on bees and aforementioned solvent effects. In other studies, DMSO has shown to have colony-level effects on bees such as increased mortality of workers and decreased eclosion of adult bees in colonies treated with DMSO-laced sucrose solution, ${ }^{43}$ and increased sterility of queen bees reared from spermatozoa stored in DMSO. ${ }^{44}$ Future work with technical- grade chlorantraniliprole should be carried out using another solvent such as acetone or a lower concentration of DMSO, although that means the concentration of active ingredient will not be as high as used in this study.

Overall, this study sought to determine effects of oral exposure to chlorantraniliprole active and formulated products to the survivability and locomotion of honey bees in the laboratory using a short (4 h) or long (72 h) exposure period. We found that chlorantraniliprole active and three formulated products were not acutely toxic to bees when exposed orally for $72 \mathrm{~h}$. Survival in newly emerged bees was measured over 30 days after either exposure period and we found that the short exposure of bees to any chlorantraniliprole treatment did not affect their survival relative to controls whereas the long exposure resulted in decreased survival of bees treated with 5SC and 20SC compared to untreated controls and active ingredient relative 
to solvent controls. Lastly, the distance moved by bees in a Petri dish arena at 24, 48, and $72 \mathrm{~h}$ after initial exposure was recorded. Bees treated with a short exposure to active ingredient had significantly decreased locomotion at 48 and $72 \mathrm{~h}$ compared to the solvent control, likely due in part to solvent effects, and bees treated with 35WG moved significantly less at $24 \mathrm{~h}$ than untreated control but recovered at 48 and $72 \mathrm{~h}$. Bees treated with a longer exposure to active ingredient had significantly decreased movement at $24 \mathrm{~h}$ but distance traveled decreased similarly in active ingredient and solvent control bees at 48 and $72 \mathrm{~h}$; bees treated with all three chlorantraniliprole formulations, 5SC, 20SC, and 35WG, had consistently decreased locomotion compared to untreated controls over all time points.

Future experiments are needed to confirm the reduced locomotor activities observed with laboratory-treated bees to effects that might result from a field colony being exposed to chlorantraniliprole. These experiments would require exposure of semi- or full-field colonies to chlorantraniliprole active and formulated products through multiple routes of exposure (feeding or spraying) aimed at quantifying differences in locomotor activities resulting in behavioral deficits that might compromise the productivity, health, and fitness of the colony. These additional locomotor activity endpoints may include flight, navigation, learning, grooming, dancing, or other behaviors that are essential for maintaining a healthy, productive colony. For example, multiple studies have reported neonicotinoid insecticides such as imidacloprid and thiamethoxam affect the movement, foraging, learning capability, sucrose responsiveness, and grooming behavior of bees..$^{20,45-48}$ Moreover, de Mattos et al. observed a reduction in grooming behavior for bees exposed to the acaricide coumaphos. ${ }^{49}$ The data gathered from semi- and full-field experiments examining the locomotor activities of chlorantraniliprole-exposed bees may elucidate the downstream effects of this neuromuscular insecticide on foraging and hygienic behaviors linked to the productivity and sustainability of healthy bee colonies. The value added by bee pollination to agriculture, the increasing use of diamide insecticides across agricultural and nonagricultural landscapes, and the unique mode of action of these insecticides necessitates investigation into the potential sublethal effects that exposure may have on the overall productivity, health, and fitness of these pollinators. 


\section{References}

1 Klein A-M, Vaissière BE, Cane JH, Steffan-Dewenter I, Cunningham SA, Kremen C et al., Importance of pollinators in changing landscapes for world crops. Proc $R$ Soc B Biol Sci 274:303-313 (2007).

2 Calderone NW, Insect pollinated crops, insect pollinators and US agriculture: trend analysis of aggregate data for the period 1992-2009. PLoS One 7:e37235 (2012).

3 Aizen MA and Harder LD, The global stock of domesticated honey bees is growing slower than agricultural demand for pollination. Curr Biol 19:915-918 (2009).

4 Potts SG, Imperatriz-Fonseca V, Ngo HT, Aizen MA, Biesmeijer JC, Breeze TD et al., Safeguarding pollinators and their values to human well-being. Nature 540:220-229 (2016).

5 Williams PH and Osborne JL, Bumblebee vulnerability and conservation worldwide. Apidologie 40:367-387 (2009).

6 Goulson D, Nicholls E, Botías C and Rotheray EL, Bee declines driven by combined stress from parasites, pesticides, and lack of flowers. Science 347:1255957 (2015).

7 Seitz N, Traynor KS, Steinhauer N, Rennich K, Wilson ME, Ellis JD et al., A national survey of managed honey bee 2014-2015 annual colony losses in the USA. J Apic Res 54:292-304 (2015).

8 Mullin CA, Frazier M, Frazier JL, Ashcraft S, Simonds R and Pettis JS, High levels of miticides and agrochemicals in North American apiaries: implications for honey bee health. PLoS One 5:e9754 (2010).

9 Sanchez-Bayo F and Goka K, Pesticide residues and bees - a risk assessment. PLoS One 9:e94482 (2014).

10 Ostiguy N, Drummond FA, Aronstein K, Eitzer B, Ellis JD, Spivak M et al., Honey bee exposure to pesticides: a four-year nationwide study. Insects 10:13 (2019).

11 Locke B, Forsgren E, Fries I and de Miranda JR, Acaricide treatment affects viral dynamics in Varroa destructor-infested honey bee colonies via both host physiology and mite control. Appl Environ Microbiol 78:227-235 (2012).

12 Boncristiani H, Underwood R, Schwarz R, Evans JD and Pettis J, Direct effect of acaricides on pathogen loads and gene expression levels in honey bees Apis mellifera. J Insect Physiol 58: 613-620 (2012).

13 O'Neal ST, Brewster CC, Bloomquist JR and Anderson TD, Amitraz and its metabolite modulate honey bee cardiac function and tolerance to viral infection. J Invertebr Pathol 149:119-126 (2017).

14 O'Neal ST, Reeves AM, Fell RD, Brewster CC and Anderson TD, Chlorothalonil exposure alters virus susceptibility and markers of immunity, nutrition, and development in honey bees. J Insect Sci 19:14 (2019).

15 O'Neal S, Anderson TD and Wu-Smart JY, Interactions between pesticides and pathogen susceptibility in honey bees. Curr Opin Insect Sci 26:57-62 (2018). 
16 Reeves AM, O'Neal ST, Fell RD, Brewster CC and Anderson TD, In-hive acaricides alter biochemical and morphological indicators of honey bee nutrition, immunity, and development. J Insect Sci 18:1-6 (2018).

17 Johnson RM, Pollock HS and Berenbaum MR, Synergistic interactions between in-hive miticides in Apis mellifera. J Econ Entomol 102: 474-479 (2009).

18 Johnson RM, Dahlgren L, Siegfried BD and Ellis MD, Acaricide, fungicide and drug interactions in honey bees (Apis mellifera). PLoS One 8:e54092 (2013).

19 Wade A, Lin C-H, Kurkul C, Regan ER and Johnson RM, Combined toxicity of insecticides and fungicides applied to California almond orchards to honey bee larvae and adults. Insects 10:20 (2019).

20 Decourtye A, Devillers J, Genecque E, Le Menach K, Budzinski H, Cluzeau S et al., Comparative sublethal toxicity of nine pesticides on olfactory learning performances of the honeybee Apis mellifera. Arch Environ Contam Toxicol 48:242-250 (2005).

21 Henry M, Beguin M, Requier F, Rollin O, Odoux J-F, Aupinel P et al., A common pesticide decreases foraging success and survival in honey bees. Science 336:348-350 (2012).

22 Pettis JS, Lichtenberg EM, Andree M, Stitzinger J, Rose R and van Engelsdorp $D$, Crop pollination exposes honey bees to pesticides which alters their susceptibility to the gut pathogen Nosema ceranae. PLoS One 8:e70182 (2013).

23 Kakumanu ML, Reeves AM, Anderson TD, Rodrigues RR and Williams MA, Honey bee gut microbiome is altered by in-hive pesticide exposures. Front Microbiol 7:1255 (2016).

24 Wilson JM, Anderson TD and Kuhar TP, Sublethal effects of the insecticide pyrifluquinazon on the European honey bee (Hymenoptera: Apidae). J Econ Entomol 112:1050-1054 (2019).

25 Sparks TC and Nauen R, IRAC:mode of action classification and insecticide resistance management. Pestic Biochem Physiol 121:122-128 (2015).

26 Cordova D, Benner EA, Sacher MD, Rauh JJ, Sopa JS, Lahm GP et al., Anthranilic diamides: a new class of insecticides with a novel mode of action, ryanodine receptor activation. Pestic Biochem Physiol 84: 196-214 (2006).

27 Lahm GP, Stevenson TM, Selby TP, Freudenberger JH, Cordova D, Flexner L et al., Rynaxypyr ${ }^{\mathrm{TM}}$ : a new insecticidal anthranilic diamide that acts as a potent and selective ryanodine receptor activator. Bioorg Med Chem Lett 17:62746279 (2007).

28 Sattelle DB, Cordova D and Cheek TR, Insect ryanodine receptors: molecular targets for novel pest control chemicals. Invert Neurosci 8:107-119 (2008).

29 Qi S and Casida JE, Species differences in chlorantraniliprole and flubendiamide insecticide binding sites in the ryanodine receptor. Pestic Biochem Physiol 107:321-326 (2013).

30 Troczka BJ, Richardson E, Homem RA and Davies TE, An analysis of variability in genome organisation of intracellular calcium release channels across insect orders. Gene 670:70-86 (2018). 
31 Nauen R and Steinbach D, Resistance to diamide insecticides in lepidopteran pests, in Advances in Insect Control and Resistance Management, ed. by Horowitz A and Ishaaya I, Springer, Cham, pp. 219-240 (2016).

32 Dinter A, Brugger KE, Frost N-M and Woodward MD, Chlorantraniliprole (Rynaxypyr): a novel DuPont ${ }^{\mathrm{TM}}$ insecticide with low toxicity and low risk for honey bees (Apis mellifera) and bumble bees (Bombus terrestris) providing excellent tools for uses in integrated pest management. Julius Kühn Archiv 14:84-96 (2009).

33 Larson JL, Redmond CT and Potter DA, Assessing insecticide hazard to bumble bees foraging on flowering weeds in treated lawns. PLoS One 8:e66375 (2013).

34 Larson JL, Redmond CT and Potter DA, Impacts of a neonicotinoid, neonicotinoid-pyrethroid premix, and anthranilic diamide insecticide on four species of turf-inhabiting beneficial insects. Ecotoxicology 23:252-259 (2014).

35 Zhu YC, Adamczyk J, Rinderer T, Yao J, Danka R, Luttrell R et al., Spray toxicity and risk potential of 42 commonly used formulations of row crop pesticides to adult honey bees (Hymenoptera: Apidae). J Econ Entomol 108:2640-2647 (2015).

36 Smagghe G, Deknopper J, Meeus I and Mommaerts V, Dietary chlorantraniliprole suppresses reproduction in worker bumblebees. Pest Manag Sci 69:787-791 (2013).

37 Kadala A, CharretonM, Charnet P and Collet C, Honey bees long-lasting locomotor deficits after exposure to the diamide chlorantraniliprole are accompanied by brain and muscular calcium channels alterations. Sci Rep 9:2153 (2019).

38 Larson NR and Anderson TD, Video tracking protocol to screen deterrent chemistries for honey bees. J Vis Exp 124:e55603 (2017).

39 Sponsler DB and Johnson RM, Mechanistic modeling of pesticide exposure: the missing keystone of honey bee toxicology. Environ Toxicol Chem 36:871881 (2018).

40 Sponsler DB, Grozinger CM, Hitaj C, Rundlöf M, Botías C, Code A et al., Pesticides and pollinators: a socioecological synthesis. Sci Total Environ 662:1012-1027 (2019).

41 Kopit AM and Pitts-Singer TL, Routes of pesticide exposure in solitary, cavitynesting bees. Environ Entomol 47:499-510 (2018).

42 Duke SO, Pesticide Dose-A parameter with many implications, Pesticide Dose: Effects on the Environment and Target and Non-Target Organisms. ACS Publications, Washington, pp. 1-13 (2017).

43 Milchreit K, Ruhnke H, Wegener J and Bienefeld K, Effects of an insect growth regulator and a solvent on honeybee (Apis mellifera L.) brood development and queen viability. Ecotoxicology 25: 530-537 (2016).

44 Harbo JR, Sterility in honey bees caused by dimethyl sulfoxide. J Hered 77:129130 (1986). 
45 Yang EC, Chuang YC, Chen YL and Chang LH, Abnormal foraging behavior induced by sublethal dosage of imidacloprid in the honey bee (Hymenoptera: Apidae). J Econ Entomol 101: 1743-1748 (2008).

46 Schneider CW, Tautz J, Grünewald B and Fuchs S, RFID tracking of sublethal effects of two neonicotinoid insecticides on the foraging behavior of Apis mellifera. PLoS One 7:e30023 (2012).

47 Aliouane Y, El Hassani AK, Gary V, Armengaud C, Lambin M and Gauthier M, Subchronic exposure of honeybees to sublethal doses of pesticides: effects on behavior. Environ Toxicol Chem Int J 28: 113-122 (2009).

$48 \mathrm{Wu}$-Smart J and Spivak M, Sub-lethal effects of dietary neonicotinoid insecticide exposure on honey bee queen fecundity and colony development. Sci Rep 6:1-11 (2016).

49 De Mattos, IM, Soares, AEE and Tarpy DR. Effects of synthetic acaricides on honey bee grooming behavior against the parasitic Varroa destructor mite. Apidologie 48(4) 483-494 (2017). 